Arch. Met. Geoph. Biocl., Ser. B, 32, 263-278 (1983)

ARCHIVES
FOR METEOROLOGY,
GEOPHYSICS, AND
BIOCLIMATOLOGY
by Springer-Verlag 1983

$551.521 .32: 551.584 .31$

Great Lakes Environmental Research Laboratory and Department of Geological Sciences, University of Michigan, Ann Arbor, Michigan, U.S.A.

\title{
Performance of a Frost Hollow as a Hemispherical Thermal Radiometer
}

\author{
G. Greene and F. Nelson \\ With 6 Figures \\ Received November 18,1982
}

\section{Summary}

Radiant sky hemispheric temperature, snow-surface temperature, and thermal profiles within the snowpack were measured at night in a frost hollow in southeastern Michigan, U.S.A. Snow-surface temperatures remained $3^{\circ}$ to $5^{\circ} \mathrm{C}$ colder than air temperatures at $3 \mathrm{~m}$ above the snow surface and $6^{\circ}$ to $7^{\circ} \mathrm{C}$ colder than air temperatures at $18 \mathrm{~m}$, the height of the hollow's rim above its floor. Due to suppression of turbulent heat transfer, the energy balance at the surface was dominated by net longwave radiation; energy involved in sensible heat transfer through the snow was equal to only about $10 \%$ of the incoming longwave radiation. Incoming longwave radiation can be expressed as a linear function of surface temperature by means of a regression equation, which yields a coefficient of determination of 0.75 .

\section{Zusammenfassung}

\section{Die Wirkung einer Frostmulde als hemisphärisches thermisches Radiometer}

Die Strahlungstemperatur der Himmelshemisphäre, die Schneeoberflächentemperatur und thermische Profile in der Schneedecke wurden in einer klaren Nacht in einer Frostmulde im Südosten von Michigan, U.S.A., gemessen. Die Schneeoberflächentemperatur blieb 3 bis $5^{\circ} \mathrm{C}$ kälter als die Lufttemperatur in $3 \mathrm{~m}$ über der Schneeoberfläche und um 6 bis $7{ }^{\circ} \mathrm{C}$ kälter als die Lufttemperatur in $18 \mathrm{~m}$ Höhe, das ist die Höhe des oberen Randes der Mulde über ihrem Boden. Bei Bestimmung der turbulenten Wärmeübertragung war der Energiehaushalt an der Oberfläche von der langwelligen Strahlungsbilanz beherrscht. Die mit dem Transport fühlbarer Wärme durch den Schnee verbundene Energie betrug nur ungefähr $10 \%$ der langwelligen Einstrahlung. Die langwellige Einstrahlung kann durch eine lineare Funktion der Oberflächentemperatur mittels einer Regressionsgleichung ausgedriickt werden, die einen Regressionskoeffizienten von 0,75 ergibt. 


\section{Introduction}

Topography has long been recognized to exert an important influence on local climate. A classic example of terrain-climate interaction is the "frost hollow", a closed topographic depression experiencing a greater range of temperatures than its surroundings. Of particular interest to investigators in agriculture and botany are the extremely low temperatures found in such hollows [7, 13].

Much of the research on frost hollows has been concerned with documenting the existence of temperature inversions or extreme temperature minima $[5,20,24]$; little has been done to evaluate the energy balance in such topographic features. This paper describes the energy balance within a frost hollow during the simplest of cases: at night under clear-sky winter conditions. Under such conditions the hollow was hypothesized to behave in a manner such that snow-surface temperatures could be described largely as a function of the net radiation exchange. Such behavior would make the hollow's operation analogous to that of the simple hemispherical radiometers described by Sellers [19].

\section{Previous Studies}

Geiger [10] has succinctly summarized much of the earlier German-language literature dealing with frost-hollow phenomena. The low temperatures experienced in terrain depressions may be ascribed to four factors: 1) ponding of cold air; 2) attenuation of counterradiation due to topographic screening; 3) reduction of turbulent exchange; and 4) a decrease in the quantity of incident beam radiation due to shadowing.

Although the energy radiated and conducted from flanking slopes may be a significant input to the energy balance of some hollows, it is usually overcompensated by the other factors [19]. The interaction of these elements varies with the size and configuration of the basin [4].

Most of the frost-hollow literature, especially that published in the English language, is of a strongly applied nature, and is largely concerned with documenting the existence of temperature inversions and extreme minima within the hollows, or with statistical prediction of conditions hazardous to crops. Two primary methods have been employed for investigating frost hollows. One approach uses temperature data from fortuitously-located meteorological stations, treating them in terms of the relative frequency of frost events. Such studies are typified by the work of Albright and Stoker [1], who obtained 5800 observations of temperatures minima at both the floor and rim of a frost pocket in northern Alberta. The duration of frostfree weather at the upper station exceeded that of the lower by a factor of 
three. Similar results were obtained by Catchpole [5] and by Smith [20], the latter investigator showing the magnitude of the thermal contrast between the floor and rim to average four times that between the rim and a sidewall.

A second approach to the study of frost hollows involves use of a mobile platform, usually an automobile, to obtain temperature observations at a large number of sites on a single night $[11,12,16]$. This line of investigation allows development of regression equations relating temperature to elevation, and fills in details of temperature inversions without the necessity for extrapolating between widely-spaced points. Harrison [11] used a network of voluntary observers to record temperatures at 21 stations over a two-year period and derived a set of predictive equations for temperature variation with elevation under several gross weather types. A variant of this method was employed by Laughlin [15], who used 14 minimum-temperature thermometers to examine the spatial variability of low temperatures over a variety of topographic and vegetation-cover sites.

This brief review indicates that most studies of frost hollows have been conducted using strongly empirical methodological frameworks. Since only near-surface temperature data were scrutinized, conclusions regarding the underlying factors were reached largely by intuitive means. Unfortunately, simple temperature measurements at various terrain positions will do little to further our knowledge of the physical mechanisms involved in the frosthollow phenomenon. This paper makes an initial examination of the nocturnal energy balance in a frost hollow under clear-sky winter conditions. The motivation for the investigation was the hypothesis that under such conditions the behavior of a snow-covered topographic depression would be very similar to that of a simple hemispherical radiometer.

\section{Setting and Methods}

Investigations were performed in the E.S. George Reserve, a University of Michigan research facility located in southeastern Michigan at approximately $42^{\circ} 30^{\prime} \mathrm{N}, 84^{\circ} 00^{\prime} \mathrm{W}$. The George Reserve lies within a glacial interglobate area where widespread ice disintegration occurred during the Woodfordian substage of the Wisconsin glaciation. Landforms in the locality strongly reflect this origin, with considerable relief generated by the juxtaposition of kames, kettles, and amorphous deposits of collapse drift.

The existence of the frost-hollow phenomenon has been demonstrated previously [6] in a large kettle, "Buck Hollow", which forms the setting for the present study (Fig. 1). This topographic depression assumes a nearlycircular plan form, with vertical relief approaching $20 \mathrm{~m}$ from the floor 


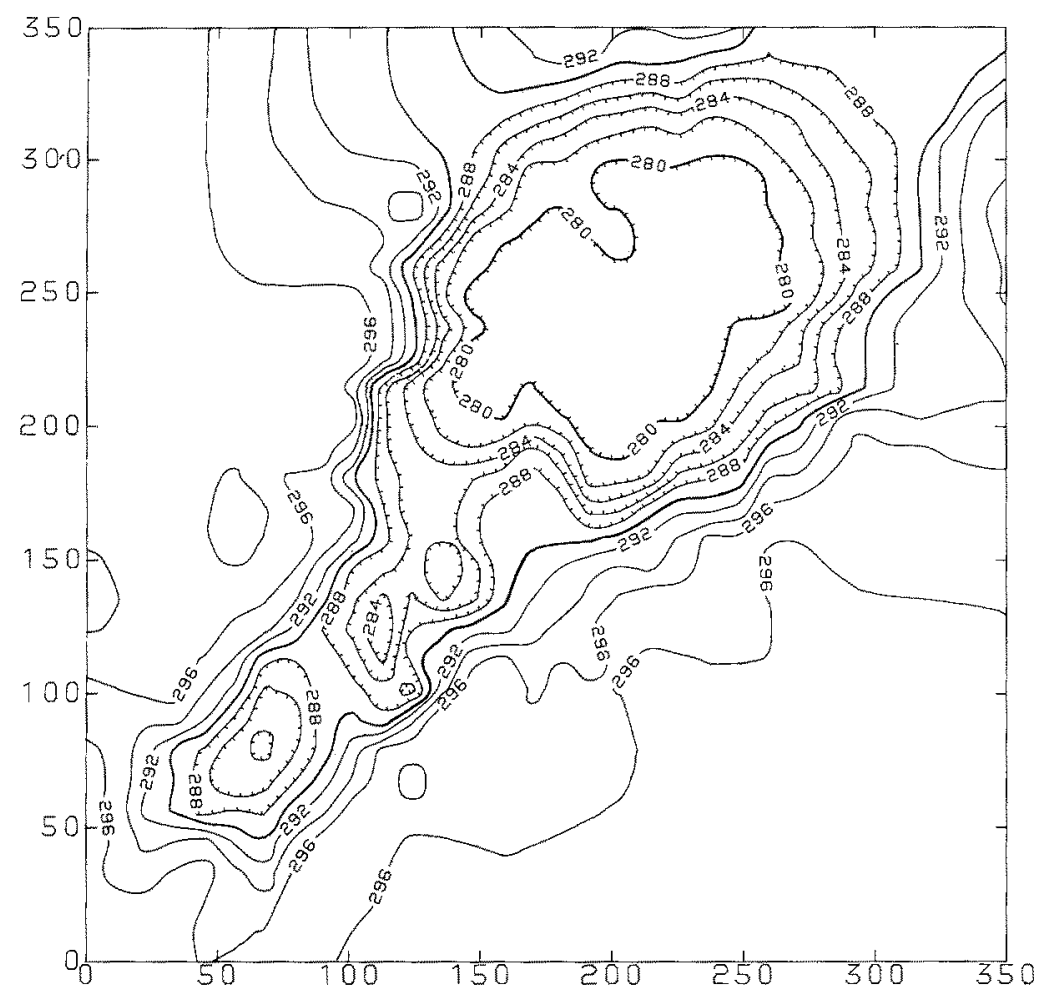

Fig. 1. Topographic map of Buck Hollow in the George Reserve, near Pinckney, Michigan. Elevation is given in meters above sea level; units along map borders are meters from an arbitrary origin at the southwest corner of the map area. Instrument tower is located near center of hollow floor

( 278 m.a.s.l.) to the $\operatorname{rim}(296 \mathrm{~m})$. Horizon angles measured from the base of the instrument tower at the eight cardinal points were (clockwise from north) $32^{\circ}, 27^{\circ}, 20^{\circ}, 20^{\circ}, 15^{\circ}, 15^{\circ}, 24^{\circ}$, and $33^{\circ}$, yielding a sky-hemisphere view factor of 0.85 [18]. Due to poor drainage, the floor is composed of unwooded bogland. The surrounding slopes are heavily forested with secondgrowth oak and hickory.

An existing $46 \mathrm{~m}$ meteorological tower located near the center of the kettle floor was used to obtain vertical air-temperature profiles. Yellow Springs Instruments (Y.S.I.) series 400 thermistors were at tached at the 3.0, 6.0,9.0, $12.0,15.0,18.0,30.5$, and $42.5 \mathrm{~m}$ levels, wired to a switching box at the tower base, and read with a Y.S.I. Tele-Thermometer. Sky hemisphere radiant temperature was taken as the average of nine readings; one at zenith, 
the others at $15^{\circ}$ and $45^{\circ}$ elevations above each of the cardinal compass directions. This temperature, $T_{s k y}$, represents an integrated temperature for the entire radiating hemisphere, including the forested slopes of the hollow, and was $3^{\circ}$ to $4{ }^{\circ} \mathrm{C}$ warmer than the radiant sky temperature at the zenith. Readings were made with a Barnes PRT-10-B radiation thermometer (Barnes Engineering Company). Snow temperatures were obtained using Y.S.I. series 400 thermistors placed on the kettle bottom at $0,-4,-5,-10,-21$, -31 , and $-40 \mathrm{~cm}$ in the snowpack. Staggered depths were necessary due to ice layers; thermistors were implanted as close to their upper and lower boundaries as possible. Wind speeds were measured using a hand-held magnetic drag cup-type anemometer with a starting threshold of $0.5 \mathrm{~m} \mathrm{~s}^{-1}$. Field measurements were made at hourly intervals during the night of $27-28$ February, 1979, commencing at 2200 and continuing until 0800 (Eastern Standard Time). Clear-sky conditions prevailed during the entire observation period. During the previous daylight period, sunshine was $100 \%$ of that possible at Lansing ( $48 \mathrm{~km}$ distant), the nearest National Weather Service Station [23]. The snowpack at the time of observation was 40 and $34 \mathrm{~cm}$ thick on the kettle floor and rim, respectively.

Observation procedures involved reading air temperatures at all tower levels, followed by measurements of sky radiant temperature and kettle-floor snowtemperature profiles. Although measurement of air temperature, sky radiant temperature, and kettle-bottom snow temperature took place over a three to four minute period, the measurements were treated as if taken simultaneously. This assumption was considered reasonable due to a virtual absence of wind and cloud cover.

\section{Theory}

On clear winter nights, a useful analogy to the frost-hollow phenomenon is the operation of a simple upward-facing radiometer [19]. The absorbing surface of such an instrument is insulated on all sides except the face. The face is covered by polyethylene, preventing turbulent heat exchange and allowing both longwave and shortwave radiation to be transmitted. Surface temperature is measured by a thermistor in contact with the absorbing surface. In a simple radiometer tested by Suomi and Kuhn [21], sensible heat conducted through the insulation contributed roughly ten percent of the surface energy flux. The bulk of the energy flux at the absorbing surface can therefore arrive only in the form of radiation.

In order for the snow surface in a regularly-shaped topographic depression to sense sky thermal radiation in an analogous manner, a layer of snow must be present to insulate the surface from ground heat flux, and a strong inversion 
must be present to suppress turbulent air motion close to the ground. When these conditions occur at night, the snow surface is striving to reach thermal equilibrium with the sky hemisphere. These conditions are presented schematically in Fig. 2. Although the sides of the hollow were insulated by snow, the slopes were covered by mature hardwoods more closely coupled to the air temperature than the snow surface was.

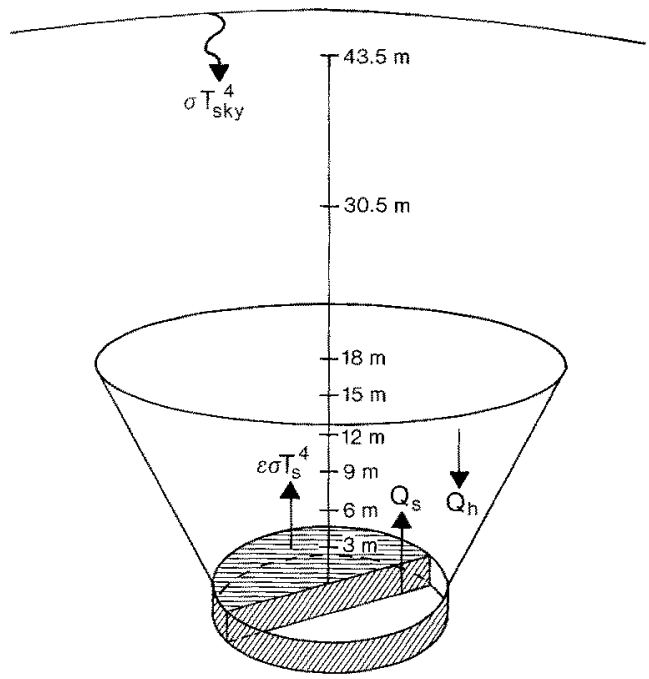

Fig. 2. Schematic view of nocturnal energy fluxes in Buck Hollow

A common first estimate of the sky radiant temperature is $22^{\circ} \mathrm{C}$ below the air temperature [17], suggesting that extremely cold temperatures could be found in the bottom of the kettle. However, the surface temperature is prevented from becoming as low as the sky radiant temperature because the graybody nature of snow, imperfect insulation by the snow cover, and the presence of turbulent energy transfer fluxes all tend to raise the surface temperature.

The governing energy-balance equation relating these processes when no snowmelt is taking place is given by

$$
Q_{r n}+Q_{h}+Q_{l e}+Q_{s}=0.0,
$$

where $Q_{n n}$ represents the net radiation flux, $Q_{h}$ is sensible heat flux to the atmosphere, $Q_{l e}$ is evaporative heat flux, and $Q_{s}$ is the sensible heat flux transferred between the snowpack and the snow surface. All fluxes are 
given in the units $\mathrm{W} \mathrm{m}^{-2}$ and follow the convention that any flux toward the surface is a positive value.

Under conditions of no turbulent transfer to the surface, one can compute a surface temperature, $T^{\prime}$, at which a balance between incoming $\left(Q_{l w d}\right)$ and outgoing $\left(Q_{l w u}\right)$ longwave radiation would occur. If the net radiation flux is zero and no shortwave radiation is present, this relationship can be denoted by

$$
\sigma\left(T_{s k y}+273\right)^{4}=\epsilon \sigma\left(T_{s}+273\right)^{4},
$$

where $T_{s}$ is the surface temperature $\left({ }^{\circ} \mathrm{C}\right), \sigma$ is the Stefan-Boltzmann constant $\left(5.673 \cdot 10^{-8} \mathrm{~W} \mathrm{~m}^{-2} \mathrm{~K}^{-4}\right)$, and $\epsilon$ is the snow's surface emissivity. Solving for $T_{s}$ results in

$$
T_{s}=T^{\prime}=\left(\left(T_{\text {sky }}+273\right) / \epsilon^{0.25}\right)-273 .
$$

Note that $T^{\prime}$ will always be slightly warmer than $T_{s k y}$ because the emissivity of snow is less than unity.

Unless the pack is isothermal, additional warming of the snow surface will occur due to sensible heat transfer through the snow cover. Basic principles suggest that any flux to the snow surface will be a function of both the snow thickness and the thermal properties of the layer.

Fleagle [9] defined $T_{m}$, the minimum possible surface temperature, as a function of the temperature gradient in the snowcover, the thermal conductivity $(K)$ of the snow layer, and the emitted longwave radiation. Once equilibrium (linear temperature gradient) is at tained

$$
T_{m}=\left(Z_{s} T^{\prime}+d T_{b}\right) /\left(Z_{s}+d\right),
$$

where $Z_{s}$ is the thickness of the snow layer $(\mathrm{m}), T_{b}$ is the temperature at the base of the snow layer $\left({ }^{\circ} \mathrm{C}\right)$, and $d$ is defined by

$$
d=K /\left(4 \sigma\left(T^{\prime}+273\right)^{3}\right) \text {. }
$$

For a given snow layer, the difference between $T_{m}$ and $T^{\prime}$ is largely a function of the snow thickness. Consider, for example, a layer of snow with $K=0.268 \mathrm{~W} \mathrm{~m}^{-1}{ }^{\circ} \mathrm{C}^{-1}, T_{b}=-0.1{ }^{\circ} \mathrm{C}$, and $T^{\prime}=-15.0^{\circ} \mathrm{C}$. Using eq. (4), a snow layer $5 \mathrm{~cm}$ thick would have $T_{m}$ equal to $-6.4^{\circ} \mathrm{C}$. If the snow thickness increased to $200 \mathrm{~cm}, T_{m}$ would be $-14.5^{\circ} \mathrm{C}$, still $0.5^{\circ} \mathrm{C}$ warmer than $T^{\prime}$, the temperature of zero net radiation.

The final case for consideration allows for turbulent transfer of heat as well as sensible heat flux in the snow and the net radiation flux. When wind speeds are observed at only one level, the turbulent flux relation can be computed as follows

$$
\begin{aligned}
& Q_{h}=-\rho_{a} c_{a} U C_{h}\left(T_{a}-T_{s}\right) \\
& Q_{l e}=-\rho_{a} L U C_{l e}\left(q_{a}-q_{s}\right)
\end{aligned}
$$


where $\rho_{a}=$ air density $\left(\mathrm{kg} \mathrm{m}^{-3}\right), c_{a}=$ specific heat of air at constant pressure $\left(\mathrm{J} \mathrm{kg}^{-1}{ }^{\circ} \mathrm{C}^{-1}\right), U=$ wind speed $\left(\mathrm{m} \mathrm{s}^{-1}\right), T_{a}=$ air temperature $\left({ }^{\circ} \mathrm{C}\right)$, $L=$ latent heat of vaporization $\left(\mathrm{J} \mathrm{kg}^{-1}\right), q=$ specific humidity and $C_{h}$ and $C_{l e}$ are bulk transfer coefficients [2].

Once the turbulent flux relations are added to the energy-balance equation, it is no longer feasible to solve directly for $T_{s}$. However, by making the flux equations transcendental in surface temperature, a numerical method can be

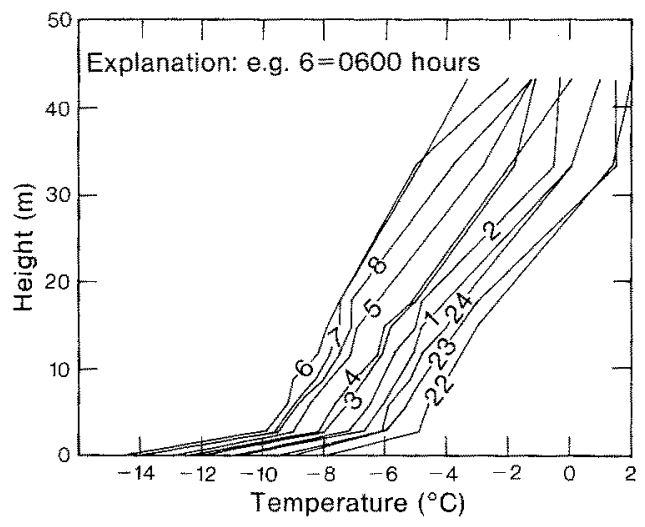

Fig. 3. Air-temperature profiles, 27-28 February 1979

used to solve for the temperature which allows the fluxes to balance, the "equilibrium surface temperature". This surface temperature and the observed temperature at the base of the snow layer then form the boundary conditions for solution of the equation describing heat flow through the snow. The fully implicit method used was described in detail by Dozier and Outcalt [8].

\section{Results and Discussion}

\subsection{Surface Energy Fluxes}

The air-temperature profiles in Fig. 3 clearly demonstrate the existence of a pronounced temperature inversion. The temperature difference between the surface temperature and air temperature at $43.5 \mathrm{~m}$ remained $11^{\circ}$ to $12{ }^{\circ} \mathrm{C}$ throughout the night. No wind was detected by our instrument (starting velocity $0.5 \mathrm{~m} \mathrm{~s}^{-1}$ ) throughout the observation period. Dried plant stems protruding 0.3 to $0.5 \mathrm{~m}$ above the snowpack displayed no motion, supporting the contention that a strong inversion would suppress turbulent transfer. 


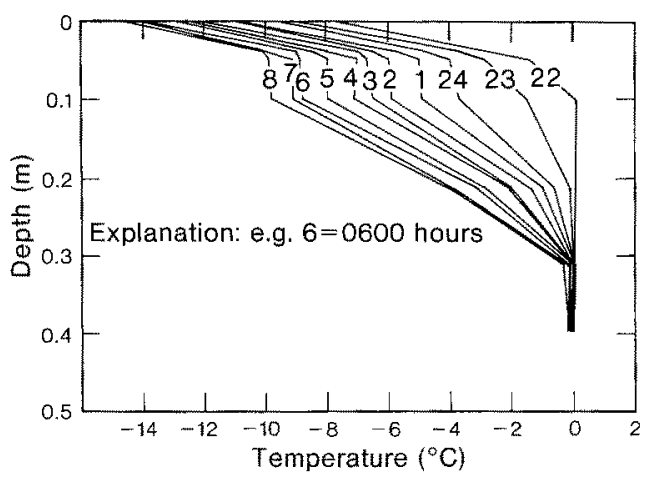

Fig. 4. Snow-temperature profiles, 27-28 February 1979

Table 1. Observed Radiant Sky Temperature $\left(T_{\text {sky }}\right)$, Computed Temperature of Zero Net Radiation $\left(T^{\prime}\right)$, Computed Minimum Surface Temperature $\left(T_{m}\right)$, and Observed Surface Temperature $\left(T_{s}\right)$ over the Observation Period. Note the general decrease in the quantity $\left(T_{s}-T_{m}\right)$ over the period of observation

\begin{tabular}{llllll}
\hline Time & $T_{s k y}$ & $T^{\prime}$ & $T_{m}$ & $T_{s}$ & $T_{s}-T_{m}$ \\
\hline 2200 & -21.2 & -17.9 & -12.8 & -8.0 & 4.8 \\
2300 & -20.3 & -17.0 & -12.2 & -9.1 & 3.1 \\
2400 & -20.3 & -17.0 & -12.2 & -9.6 & 2.6 \\
0100 & -22.4 & -19.2 & -13.7 & -11.0 & 2.7 \\
0200 & -20.9 & -17.6 & -12.6 & -11.0 & 1.6 \\
0300 & -22.2 & -19.0 & -13.6 & -12.2 & 1.4 \\
0400 & -23.7 & -20.5 & -14.5 & -12.6 & 1.9 \\
0500 & -24.7 & -21.5 & -15.2 & -13.0 & 2.2 \\
0600 & -26.9 & -23.7 & -16.6 & -14.0 & 2.6 \\
0700 & -24.6 & -21.4 & -15.1 & -14.5 & 0.6 \\
0800 & -24.3 & -21.1 & -14.9 & -14.0 & 0.9
\end{tabular}

Fig. 4 illustrates the thermal evolution of the snow layer during the observation period. A recurring feature of the profiles is the near-isothermal layer between 5 and $10 \mathrm{~cm}$ below the surface. This stratum lay beneath a thin layer of ice, which appeared to have resulted from refreezing of meltwater generated at the surface during the previous daylight period. The bulk density of the snow layer was estimated to be $350 \mathrm{~kg} \mathrm{~m}^{-3}$.

Table 1 lists observed values for the radiant sky temperature and surface temperature, as well as the computed values for the temperature of zero net radiation $\left(T^{\prime}\right)$ and minimum surface temperature $\left(T_{m}\right)$. A midrange value of 
0.95 for snow emissivity was used to compute $T^{\prime}$ [19]. The snow thermal conductivity $(K)$ was assigned an artificially high value of $0.40 \mathrm{~W} \mathrm{~m}^{-1}{ }^{\circ} \mathrm{C}^{-1}$ in order to increase the effect of $Q_{s}$ on $T_{m}$.

$T^{\prime}$ and $T_{m}$ cannot be directly compared to the observed surface temperature because emissivity and conductivity were not computed for the snowpack. The differences between $T_{s}$ and $T_{m}$ in Table 1 reveal two important points, however. Even with an artificially increased heat flow through the snowpack, $T_{m}$ remains colder than the observed surface temperature. Secondly, the

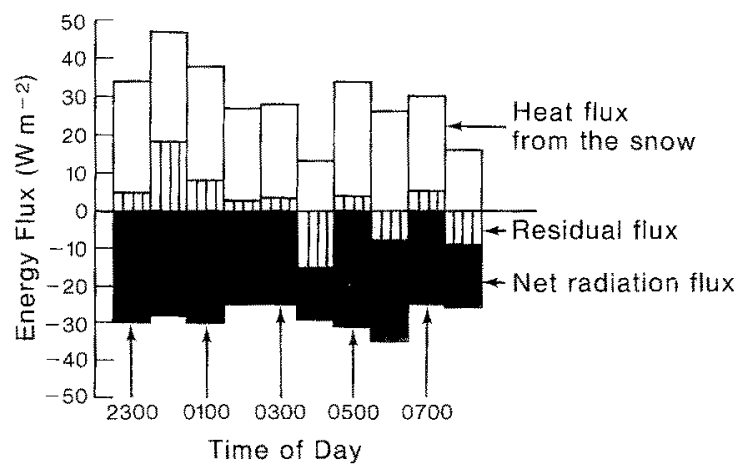

Fig. 5. Computed values of net radiation flux and sensible heat flux from the snow

difference between $T_{m}$ and $T_{s}$ tends to decrease over the observation period, reaching a minimum at 0700 . Both points suggest either that other processes are bringing energy to the surface, or that a linear gradient method underestimates $Q_{s}$ because a nonlinear gradient is present. Each possibility will be discussed in turn.

Heat flux from the snow to the snow surface was not measured directly, but can be computed by evaluating change in the temperature profile over time by

$$
Q_{s}=\int_{Z_{1}}^{Z_{2}} \rho_{s} c_{s}(\mathrm{~d} T / \mathrm{d} t) \mathrm{d} Z,
$$

where $\rho_{s}$ is snow density $\left(\mathrm{kg} \mathrm{m}^{-3}\right), c_{s}$ is the specific heat of snow $\left(\mathrm{J} \mathrm{kg}^{-1}\right.$ ${ }^{\circ} \mathrm{C}^{-1}$ ), $T$ is temperature at a given depth $Z$, and $t$ is time. This relation was integrated graphically from the snow surface to the soil-snow interface, assuming a uniform density of $350 \mathrm{~kg} \mathrm{~m}^{-3}$. The computed values for $Q_{s}$ and $Q_{m}$ are shown in Fig. 5. Incoming longwave radiation $\left(Q_{l w d}\right)$ was computed using the lefthand side of eq. (2) while outgoing longwave radiation $\left(Q_{l w u}\right)$ was computed from the righthand side. 
Table 2. Model Parameters

\begin{tabular}{ll}
\hline Parameter & Value \\
\hline Time interval & $3.6 \cdot 10^{3} \mathrm{~s}$ \\
Depth interval & $0.05 \mathrm{~m}$ \\
Snow density & $350 \mathrm{~kg} \mathrm{~m}^{-3}$ \\
Snow thickness & $0.40 \mathrm{~m}$ \\
Thermal conductivity & $0.268 \mathrm{~W} \mathrm{~m}^{-1}{ }^{\circ} \mathrm{C}^{-1}$ \\
Thermal diffusivity & $3.81 \cdot 10^{-7} \mathrm{~m}^{2} \mathrm{~s}^{-1}$ \\
Snow emissivity & 0.95 \\
Wind speed & $0.30 \mathrm{~m} \mathrm{~s}^{-1}$ \\
Aerodynamic roughness length & $7.0 \cdot 10^{-4} \mathrm{~m}$ \\
Height of wind measurement & $2.0 \mathrm{~m}$
\end{tabular}

Table 3. Simulated Values for Energy Fluxes at the Snow Surface

\begin{tabular}{llllll}
\hline Time & & & & & \\
simulated & observed \\
$Q_{r n}\left(\mathrm{~W} \mathrm{~m}^{-2}\right)$ & $Q_{s}\left(\mathrm{~W} \mathrm{~m}^{-2}\right)$ & $Q_{h}\left(\mathrm{~W} \mathrm{~m}^{-2}\right)$ & $T_{s}\left({ }^{\circ} \mathrm{C}\right)$ & $\left.T_{s}{ }^{\circ} \mathrm{C}\right)$ \\
\hline 2200 & -35.6 & 31.9 & 3.8 & -8.5 & -8.0 \\
2300 & -30.4 & 27.3 & 3.1 & -9.0 & -9.1 \\
2400 & -28.5 & 25.0 & 3.6 & -9.5 & -9.6 \\
0100 & -31.4 & 27.3 & 4.2 & -10.7 & -11.0 \\
0200 & -26.3 & 22.8 & 3.6 & -10.6 & -11.0 \\
0300 & -28.0 & 24.4 & 3.6 & -11.4 & -12.2 \\
0400 & -30.0 & 25.8 & 4.3 & -12.3 & -12.6 \\
0500 & -30.7 & 26.5 & 4.3 & -13.0 & -13.0 \\
0600 & -34.0 & 29.2 & 4.9 & -14.2 & -14.0 \\
0700 & -27.2 & 23.1 & 4.2 & -13.8 & -14.5 \\
0800 & -26.0 & 21.4 & 4.6 & -13.9 & -14.0
\end{tabular}

Both longwave radiation fluxes generally decreased over the course of the observation period as both $T_{s}$ and $T_{s k y}$ decreased. However, because $Q_{r n}$ is sensitive to slight aberrations in the rate of decrease, it ranged roughly twenty percent above and below a mean value of $-29.1 \mathrm{~W} \mathrm{~m}^{-2}$. Under steady-state conditions, the sum of $Q_{r n}$ and $Q_{s}$ represents a combination of the residual errors from calculation of these values and the flux remaining to be accounted for in the surface energy-balance relation. The residual ranged from 10 to 40 percent of the value of $Q_{s}$ except at 0400 , when the residual was larger than $Q_{s}$. Errors in the assignment of values for the snow emissivity and density could account for the magnitude of this 
residual, although such errors might be expected to assume a more constant value.

Some turbulent transfer of energy may have occurred, even though no wind was detected over the observation period. The surface energy-balance model described in the theory section was run using the parameter values listed in Table 2 ; results are given in Table 3 . A constant wind speed below the value of the sensor threshold was used to ascertain the possible magnitude of turbulent transfer. $T_{a}$ in eq. (6) was assigned the value of air temperature at the $3 \mathrm{~m}$ level. Latent heat flux was not simulated because atmospheric water vapor measurements were not taken. Values for $Q_{h}$ ranged from 3.1 to $4.9 \mathrm{~W} \mathrm{~m}^{-2}$ and are comparable in magnitude to six of the residual values.

\subsection{Frost Hollow as a Hemispherical Thermal Radiometer}

The extent to which measurable conditions within the hollow can be used to determine incoming longwave radiation can now be assessed by examining three measured and computed properties: surface energy fluxes, air temperature, and surface temperature.

When no turbulent transfer of heat is occurring at night, the energy-balance equation simplifies such that incoming longwave radiation can be determined from the heat flux in the snow layer and the emitted longwave radiation

$$
Q_{l w d}=-\left(Q_{l w u}+Q_{s}\right)
$$

Values of $Q_{l w d}$ computed from eq. (9) are listed in Table 4, and can be compared to the values determined from the measured radiant sky temperature. Virtually no correlation exists $(r=0.24)$. The disparities illustrate that $Q_{i w d}$ as determined by eq. (9) is quite sensitive to the value of $Q_{s}$, a quantity which was computed indirectly and is an order of magnitude smaller than Qlwu.

Arnfield [3] reviewed a number of methods for computing $Q_{l w d}$ from both air temperature and vapor pressure. He concluded that air temperature alone could be used to estimate hourly values for $Q_{l w d}$ under clear-sky conditions, although values would be underestimated by five to ten percent, particularly at night.

Two different relationships evaluated by Arnfield [3] were used to compute $Q_{l w d}$ from air temperatures at $3 \mathrm{~m}$ above the surface. The Swinbank [22] relation is given by

$$
Q_{l w d}=5.31 \cdot 10^{-13}\left(T_{a}+273\right)^{6} .
$$

The Idso-Jackson [14] relation is

$$
Q_{l w d}=o\left(273+T_{a}\right)^{4}\left\{1-f \exp \left[g\left(T_{a}\right)^{2}\right]\right\},
$$

where $f$ has a value of 0.261 and $g$ equals $-7.77 \cdot 10^{-4} K^{-2}$. 
Table 4. Comparison of Measured and Calculated Incoming Longwave Radiation

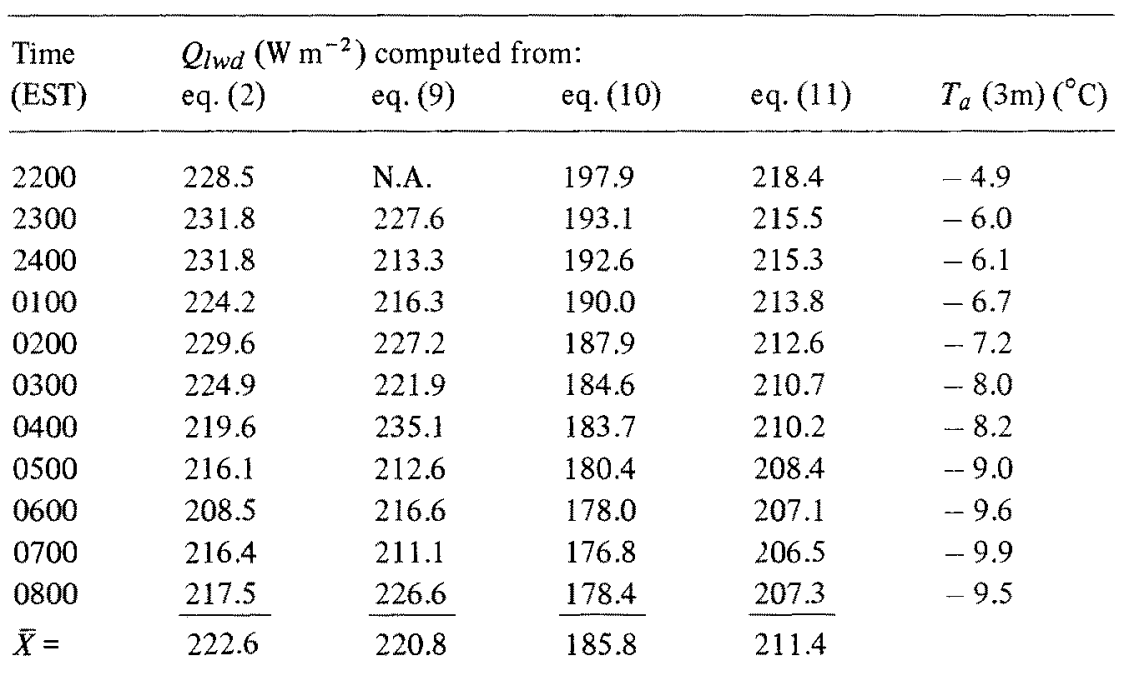

Table 4 illustrates that both relations underestimate $Q_{l w d}$ when compared to $Q_{l w d}$ as computed from the observed values of $T_{s k y}$. The Idso-Jackson relation can be applied over a broader range of air temperatures, particularly below $0{ }^{\circ} \mathrm{C}$, and approximates the "observed" $Q_{l w d}$ more closely than the Swinbank formulation. Both series of computed $Q_{l w d}$ have similar correlations with the "observed" $Q_{l w d}$; the Swinbank series yields $r=0.87$ and the Idso-Jackson series gives $r=0.86$.

The relation between surface temperature and incoming longwave radiation is shown in Fig. 6. A second-degree polynomial of the form

$$
Q_{l w d}=202.9-7.02 T_{s}-0.44 T_{s}^{2}
$$

provides the best fit $\left(r^{2}=0.81\right)$ but behaves poorly beyond the range of our data. However, both $Q_{l w u}$ and $Q_{s}$ can be approximated by linear functions of $T_{s}$. By eq. (9), $Q_{t_{w d}}$ can be considered a function of $T_{s}$ even though theoretically only the reverse is true. $T_{s}$ is more easily measured than is $Q_{l w d}$, which allows completion of the analogy with the simple radiometer. The linear regression line takes the form

$$
Q_{l w d}=258.2+3.03 T_{s}
$$

with $r^{2}=0.75$.

The absence of comparable temperature data from a site exposed to the same incoming longwave radiation but outside the frost-hollow prevents isolation of the processes which caused the depressed temperatures in the 
hollow. Rim and hollow-bottom sites exposed to the same sky hemisphere could potentially have the same surface temperature series despite a disparity between air temperatures. However, this situation is unlikely for two reasons. It is doubtful that turbulent heat transfer could be suppressed at an exposed site to the extent that it is in a sheltered hollow. Secondly, given the ponding of cold air in the frost hollow and topographically-induced differences in snow accumulation, the snow-temperature gradient in the hollow must be weaker, leading to a lower value for $Q_{s}$ than that found on the hollow rim.

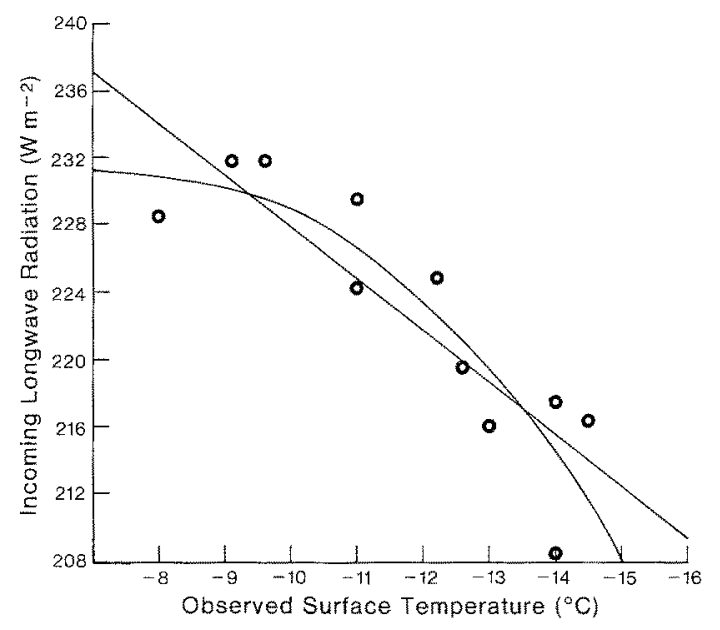

Fig. 6. Computed incoming longwave radiation, 27-28 February 1979

\section{Conclusions}

The guiding hypothesis for this investigation was that under cloudless nocturnal winter conditions, a well-developed frost hollow would operate in a manner analogous to a simple hemispherical thermal radiometer. Under this hypothesis, the snow-surface temperature at the bottom of the hollow would be affected primarily by the net radiation exchange between the snow and the sky if a thick insulating snowcover was present and no turbulent heat transfer occurred. These conditions are, of course, most likely to be met in a closed topographic depression such as the site of this investigation.

Air-temperature profiles demonstrated that a strong turbulence-suppressing inversion with a gradient of $0.2{ }^{\circ} \mathrm{C} \mathrm{m}^{-1}$ persisted above the $3 \mathrm{~m}$ level throughout the observation period. Snow-surface temperatures remained $3^{\circ}$ to $5^{\circ} \mathrm{C}$ below the air temperature at $3 \mathrm{~m}, 7^{\circ}$ to $10^{\circ} \mathrm{C}$ warmer than a 
theoretical minimum surface temperature, and $10^{\circ}$ to $13{ }^{\circ} \mathrm{C}$ warmer than the radiant sky hemisphere temperature.

Sensible heat transfer from the snow to the surface was approximately $10 \%$ of the value of incoming longwave radiation. Our calculations suggest that a snowpack of more than $1.5 \mathrm{~m}$ may be required to effectively suppress heat flux through the snow.

If all turbulent transfer was suppressed and no frost deposition occurred, the net radiation flux should be balanced by sensible heat flux from the snow. In the majority of cases the computed residual in the derived fluxes was comparable to the turbulent heat flux at a wind speed of half the threshold value of the sensor.

Although some factors thought to be responsible for the frost-hollow phenomenon, such as cold-air ponding, were not addressed in this paper, the study does provide a background against which further investigations could be performed. The writers are currently planning more comprehensive investigations of the processes responsible for the frost-hollow effect involving comparative observations on different topographic elements.

\section{Acknowledgements}

Messrs. Fred Sleator (University of Michigan) and Tom Hunt (Ohio State University) assisted with instrumentation and data collection, and contributed to the final manuscript through valuable discussions and suggestions. Dr. S. I. Outcalt (University of Michigan) critically read an earlier version of the paper. Dr. F. C. Evans (University of Michigan) kindly arranged for our use of the George Reserve and Dr. D. Portman (University of Michigan) made the anemometer available to us. The former Department of Geography in the University of Michigan provided all other instrumentation as well as computer funds for data analysis and text processing. Our thanks to all of the above.

\section{References}

1. Albright, W. D., Stoker, J. G.: Topography and Minimum Temperature. Sci. Agric. 25, 146-155 (1974).

2. Anderson, E. A.: A Point Energy and Mass Balance Model of a Snow Cover. Washington, D.C.: NOAA Tech. Report, NWS 19, 1976.

3. Arnfield, A. J.: Evaluations of Empirical Expression for the Estimation of Hourly and Daily Totals of Atmospheric Longwave Emission Under all Sky Conditions. Quart. J. R. Met. Soc. 105, 1041-1052 (1979).

4. Bolz, H. M.: Der Einfluss der infraroten Strahlung auf das Mikroklima. Abh. Met. Hydrol. Dienst D.D.R. 1, 1-59 (1951).

5. Catchpoole, A. J.: The Houghall Frost Hollow. Met. Mag. 92, 121-129 (1963).

6. Cooper, A. W.: Plant Life-Forms as Indicators of Microclimate. Ph.D. thesis, University of Michigan, 1958. 
7. Cooper, A. W.: Relationships Between Plant Life Forms and Microclimate in Southeastern Michigan. Ecol. Monogr. 31, 31-59 (1961).

8. Dozier, J., Outcalt, S. I.: An Approach Toward Energy Balance Over Rugged Terrain. Geog. Analysis 11,65-84 (1979).

9. Fleagle, R.: Radiation Theory of Local Temperature Differences. J. Met. 7, 114-120 (1950).

10. Geiger, R.: The Climate Near the Ground. Cambridge, Mass.: Harvard University Press 1965.

11. Harrison, A. A.: Variations in Night Minimum Temperatures Peculiar to a Valley in Mid-Kent. Met. Mag، 96, 257-265 (1967).

12. Hocevar, A., Martsolf, J. D.: Temperature Distribution Under Radiation Frost Conditions in a Central Pennsylvania Valley. Agric. Met. 8, 371-383 (1971).

13. Hough, A. F.: Frost Pocket and Other Microclimates in Forests of the Northern Allegheny Plateau. Ecology 26, 235-250 (1945).

14. Idso, S. B., Jackson, R. D.: Thermal Radiation from the Atmosphere. J. Geoph. Res. 74, 5397-5403 (1969).

15. Laughlin, G. P.: Minimum Temperature and Lapse Rate in Complex Terrain: Influencing Factors and Prediction. Arch. Met. Geoph. Biocl, Ser. B 30, 141-152 (1982).

16. Lawrence, E. N.: Temperatures and Topography on Radiation Nights. Met. Mag. 87 , $71-75(1958)$.

17. Ramsey, J. W., Chiang, H. D., Goldstein, R. J.: A Study of the Incoming Longwave Atmospheric Radiation from a Clear Sky. J. Appl. Met. 21, 566--578 (1982).

18. Reifsnyder, W. E., Lull, H. W.: Radiant Energy in Relation to Forests. U.S. Dept. Agr. Tech. Bull. 1344, 1-111 (1965).

19. Sellers, W. D.: Physical Climatology. Chicago: University of Chicago Press 1965.

20. Smith, K.: A Note on Minimum Screen Temperatures in the Houghall Frost Hollow. Met. Mag. 96, 300-302 (1967).

21. Suomi, V. E., Kuhn, P. M.: An Economical Net Radiometer. Tellus 10, 161-163 (1958).

22. Swinbank, W. C.: Longwave Radiation from Clear Skies. Quart. J. R. Met. Soc. 89 , $339-348$ (1963).

23. U.S. Department of Commerce: Local Climatological Data, Lansing, Michigan. Asheville,N.C.: National Climatic Center (1979).

24. Waco, D. E.: Frost Pockets in the Santa Monica Mountains of Southern California. Weather 23, 456-461 (1968).

Authors' addresses: G. Greene, Great Lakes Environmental Research Laboratory, Ann Arbor, MI 48104, U.S.A.; F. Nelson, Department of Geological Sciences, University of Michigan, Ann Arbor, MI 48109, U.S.A. 